\title{
CONTRADIÇÃO ENTRE TRABALHO E EDUCAÇÃO NA SOCIEDADE CAPITALISTA: DESNATURALIZAÇÃO DA PRECÁRIA FORMAÇÃO ESCOLAR DE JOVENS E ADULTOS TRABALHADORES
}

Graziela Lucchesi da Silva ${ }^{1}$

\section{Resumo}

O presente trabalho objetiva demonstrar, sob os fundamentos da Psicologia HistóricoCultural, que a precária formação de jovens e adultos trabalhadores é um fenômeno que só adquire significação real se entendido no quadro histórico-concreto do modo de produção capitalista. Sob esta diretriz, asseveramos que a escolarização de jovens e adultos trabalhadores, dirigida à formação de níveis mais elevados de consciência, demanda o desvelamento do processo da constituição e do desenvolvimento do modo de produção capitalista.

Palavras-chave: Formação do trabalhador, Psicologia Histórico-Cultural, Trabalho e educação.

\begin{abstract}
The current work aims at demonstrating, under the basics of the Cultural-Historical Psychology, that the precarious formation of young and adult workers is a phenomenon which only acquires real meaning if understood inside the concrete-historical frame of the capitalist production mode. Under this guideline, we assure that the education of young and adult workers towards the formation of higher awareness levels demands the unveiling of the constitution process as well as the development of the capitalist production mode.
\end{abstract}

Keywords: Worker formation, Cultural-Historical Psychology, Work and education.

\section{Introdução}

Ganha cada vez mais proficuidade, na conjuntura atual, estudos e investigações sobre um tema que nos é muito caro: a precarização da escolarização, explicitada, dentre outras situações, pelo fracasso escolar, pela evasão e pelo iletrismo.

A precarização escolar pode ser constatada em índices tais como os descritos na Síntese de Indicadores Sociais, divulgados pelo IBGE (2010a): 85,2\% dos adolescentes de 15 a 17 anos frequentavam a escola, no entanto, o percentual dos que se encontravam

\footnotetext{
${ }^{1}$ Professora Adjunta do Departamento de Psicologia da Universidade Federal do Paraná (UFPR). Doutora em Educação pela UFPR. Pesquisadora vinculada aos Grupos de Pesquisa "Psicologia Histórico-cultural e Educação/CNPQ" e "Educação e marxismo NUPE-MARX-UFPR”. E-mail: grazielaluc@ hotmail.com.
} 
no nível adequado à sua idade - ou seja, no Ensino Médio - era de 50,9\%. Em relação às taxas de abandono escolar, tanto no Ensino Fundamental quanto no Ensino Médio, a maior prevalência verificada é no Brasil ${ }^{2}$ : 3,2\% e 10\% respectivamente (IBGE, 2010a). Atrelado aos dados de abandono escolar, no Brasil, segundo o Censo Demográfico 2010, 9,6 \% (13. 940.729) da população com 15 anos ou mais é analfabeta. Na faixa de 10 a 14 anos 3,9\% (671 mil) não estavam alfabetizadas em 2010 (IBGE, 2011). Conforme a Pesquisa Nacional por Amostra de Domicílios (PNAD) 2009, a taxa de analfabetismo das pessoas de 50 anos ou mais de idade era de $21 \%$ da população (IBGE, 2010b).

Esses índices, que poderiam ser somados a tantos outros publicados pelos órgãos governamentais, dão indícios da premência da situação. No entanto, a descrição dos dados não revelam as condições objetivas que propiciam a dinâmica instalada, apenas expõe os fatos, sem explicá-los. É, por assim dizer, necessário submetê-los a uma análise crítica com o fim de explicitar as bases materiais e as contradições sociais que os produzem. Caso se atenha apenas à aparência do fenômeno ou a mera descrição dos índices, nega-se que cada fato ou evento traz em si a totalidade das relações sociais e, consequentemente, esvazia-se a possibilidade do entendimento das causas que o originam, bem como embota-se a possibilidade de enfrentamentos possíveis, em sentido prospectivo.

É, pois, com essa diretriz que abordamos, neste texto, uma decorrência específica da precarização da escolarização: a modalidade de ensino da Educação de Jovens e Adultos (EJA) ${ }^{3}$.

Do ponto de vista legal, a EJA é uma modalidade da educação básica oferecida "[...] àqueles que não tiveram acesso ou continuidade de estudos no ensino fundamental e médio na idade própria", conforme consta no artigo 37, da Lei de Diretrizes e Bases da Educação Nacional - LDB 9394/96 (BRASIL, 1996). Na mesma direção, consta nas Diretrizes Curriculares para a EJA, que esta modalidade possui especificidade própria em função do perfil e situação dos estudantes a serem atendidos, uma vez que o destinatário primeiro e maior desta modalidade é um “[...] contingente plural e

\footnotetext{
${ }^{2}$ Dentre os países pesquisados estão Argentina, Chile, Paraguai, Uruguai e Venezuela.

${ }^{3}$ O presente texto se apoia na pesquisa de doutorado "Educação de Jovens e Adultos e Psicologia HistóricoCultural: a centralidade do trabalho na aprendizagem e no desenvolvimento de trabalhadores precariamente escolarizados", defendida no Programa de Pós-Graduação em Educação da Universidade Federal do Paraná, em 2011.
} 
heterogêneo de jovens e adultos, predominantemente marcado pelo trabalho" (BRASIL, 2000, p. 27, grifos nossos).

Desprovido de fundamentação teórica precisa bem como de referência mais analítica da realidade concreta, menciona-se, no referido Documento, que a EJA representa uma “[...] dívida social não reparada para com os que não tiveram acesso a e nem domínio da escrita e leitura como bens sociais, na escola ou fora dela, e tenham sido a força de trabalho empregada na constituição de riquezas e na elevação de obras públicas" (BRASIL, 2000, p. 5, grifos nossos). Neste sentido, "fazer a reparação desta realidade, dívida inscrita em nossa história social e na vida de tantos indivíduos, é um imperativo e um dos fins da EJA porque reconhece o advento para todos deste princípio de igualdade" (BRASIL, 2000, p. 9, grifos nossos).

Lembramos que a proposição governamental referente à EJA de reparar esta “dívida social”, fundamentada no direito de "todos” os cidadãos pela educação básica não é uma questão nova na história brasileira, ao contrário, esse discurso remonta a velhas questões coadunadas à luta, cada vez mais intensa, pelo direito ao acesso aos bens sociais pela classe trabalhadora, destinatária, por primazia, da EJA.

Consideramos que a mera referência, nas Diretrizes da EJA, sobre a origem sóciohistórica da reprodução destes "excluídos", é insuficiente para a compreensão dos mecanismos que estão na origem da desigualdade social, ou seja, os mecanismos da base econômica da sociedade de classes.

Desta constatação, elaboramos o presente capítulo, cujo objetivo é discutir, sob os fundamentos do materialismo histórico-dialético e da Psicologia Histórico-Cultural, que a precária formação de jovens e adultos trabalhadores é um fenômeno que só adquire significação real se entendido no quadro histórico-concreto do modo de produção capitalista. Para tanto, organizamos o texto em três partes. Primeiramente, procuramos demonstrar que a desigualdade social, aspecto reiterativamente citado como justificativa para a proposição da EJA como política pública, é condição da sociedade de classes capitalista. Em seguida, enfatizamos que a precária formação escolar de jovens e adultos trabalhadores implica compreender a formação humana sob as determinações do trabalho. A partir destas considerações, apontamos contribuições da Psicologia Histórico-Cultural para a desnaturalização da precária formação escolar de jovens e adultos trabalhadores. 


\section{A desigualdade na sociedade de classes capitalista: a precarização da formação humana}

A precária formação humana não é questão recente na história da humanidade, não surgiu com o advento da sociedade capitalista, mas ganha nova forma e conteúdo nesta sociedade e se intensifica na crise estrutural do capital. Entender essa questão suscita o entendimento de que a desigualdade social é condição das sociedades de classes antagônicas, contudo, assume uma configuração determinada na sociedade capitalista dadas as condições de exploração do homem pelo próprio homem e da apropriação privada dos meios de produção.

Nesse sentido, a polarização entre pobreza e riqueza e, por conseguinte, a desigualdade não são recentes na história da humanidade, já que em sociedades baseadas em outros modos de produção - como por exemplo, no escravismo e no feudalismo segmentos se apropriavam da riqueza social enquanto outros extratos sobreviviam em precárias condições. São fenômenos antigos, porém não eternos. Mas, na sociedade capitalista, como indica Netto (2008), há um caráter novo e contraditório: pela primeira vez na história da humanidade produz-se massivamente a pobreza material e intelectual ao mesmo instante que estão sendo dadas as condições para sua superação.

Precisamente hoje a questão do pauperismo se generaliza e isto se deve não a herança genética desfavorável ou desinteresse intrínseco, mas, fundamentalmente, a impossibilidade de uma massa populacional de ter acesso a certos bens culturais, em função das condições objetivas do processo produtivo capitalista (KLEIN, SILVA, DA MATA, 2011).

Esse fato é candente à compreensão da EJA, pois esta modalidade de ensino emerge na sociedade capitalista e busca justamente enfrentar e minimizar as injustiças causadas pela desigualdade social, que inviabiliza uma parcela significativa de seres humanos ao acesso a um bem produzido historicamente - a leitura e escrita e os conhecimentos científicos. São justamente estes os indivíduos recorrentemente denominados nos documentos governamentais e deliberativos da EJA como "excluídos dos ensinos fundamental e médio" (BRASIL, 2000, p.4), "sujeitos marginais ao sistema" (BRASIL, 2007, p. 11) ou àqueles que devem ser dirigidos mecanismos de reparação da “dívida social" (BRASIL, 2000, p. 5), que devem ter garantido a sua "cidadania". 
A incompreensão das bases reais e concretas que fomentam as desigualdades sociais - a sociedade de classes - faz com que essas sejam entendidas como algo que devem ser combatidas em si mesmas. Neste sentido, são disseminadas, reiteradamente e secularmente, propostas governamentais e ações sociais que visam enfrentar as mazelas sociais como a fome, a violência, o desemprego estrutural, a miséria intelectual e material que assolou a humanidade no decorrer dos últimos séculos e que se apresentam em níveis mais aprofundados no atual.

No caso da educação escolar, o artifício retórico no discurso oficial dos órgãos do Estado inviabiliza a compreensão de que em uma sociedade de classes, baseada nos ideais liberais, a expansão e difusão da escola não significam que o acesso a ela tenha ocorrido nas mesmas condições para todos os indivíduos. Ao contrário, o que os fatos e os dados históricos demonstram é que as situações pedagógicas específicas existentes no interior da escola não são disponibilizadas a todos e quando disponibilizadas não ocorrem com a mesma forma e conteúdo. Isso porque na sociedade capitalista, em função da intensidade da luta de classes, não há interesses e nem possibilidades de formar indivíduos iguais, mas se busca manter a desigualdade presente (VIEIRA PINTO, 1989).

Reiteramos que a escola, não obstante fundar-se sobre determinações materiais, é difundida universalmente como se tivesse o poder de formação do cidadão, independentemente das determinações materiais. Concretamente esta predição igualitária não se efetiva, haja vista que a educação escolar chega à grande parte da população de forma superficial e rala. Isso porque a escola, nesta sociedade, não tem como finalidade cumprir as suas proclamadas funções; contudo, a sua expansão, inclusive àqueles que não tiveram acesso na idade adequada, é necessária, do ponto de vista material, como afirma Alves (2001). É neste contexto, portanto, que emerge a Educação de Jovens e Adultos.

Destas constatações, afirmamos que para além dos discursos pretensamente igualitários, é preciso entender que as condições objetivas de vida provocam um nível crescente de desumanização e ocorrem justamente pelo acirramento da contradição entre capital e trabalho e pela formação humana em caráter cada vez mais alienado. Discutir a precária formação escolar de jovens e adultos trabalhadores, desnaturalizando-a, implica, pois, compreender que a formação humana baseia-se nas determinações do trabalho. 


\section{Graziela Lucchesi da Silva}

\section{Fundamentos do materialismo histórico dialético: Ontologia do trabalho e alienação do trabalho na sociedade capitalista}

Por não dispor de espaço para uma discussão que considere os múltiplos aspectos da ontologia do trabalho, optamos pela discussão, ainda que breve, dos processos que levam à formação humana por meio da produção dos meios de vida e dos fatores que levam à alienação quando a propriedade privada dos meios de produção estabelece-se como a base para a produção e reprodução da vida.

Podemos compreender claramente em Marx e Engels a concepção de formação humana determinada pelo modo de produção de vida material, ou seja, pelo modo como os homens ${ }^{4}$ produzem a sua existência e pelas relações sociais estabelecidas neste processo, historicamente determinadas.

A definição da constituição humana parte, portanto, da existência de indivíduos humanos vivos que se destacam da natureza por produzirem intencionalmente seus meios de vida e ao produzi-los, desenvolvem a sua própria vida material, sendo este o primeiro ato propriamente humano (MARX, ENGELS, 1976).

Das objetivações criadas pelos homens, novas necessidades - bem como novas habilidades e capacidades - foram geradas e, então, novas atividades exigidas, caracterizando a formação do gênero humano interrelacionado ao processo ininterrupto da produção (DUARTE, 1993; MÁRKUS, 1974) a que podemos atribuir o papel de gerador da história humana.

A história da humanidade caracteriza-se por uma sucessão de gerações, sendo que a cada nova geração cabe a tarefa de se apropriar das objetivações elaboradas pelas anteriores, isto é, dos instrumentos, conhecimentos, funções, habilidades e técnicas que, no transcurso da atividade criadora e produtiva dos homens, objetivaram-se em produtos materiais e intelectuais (LEONTIEV, 1978). Eis que a formação da genericidade humana no indivíduo singular é possível somente pela apropriação das objetivações desenvolvidas pela humanidade, em determinado contexto. Leontiev (1978) afirma que esse processo formativo só é possível por meio da educação.

É preciso considerar que quanto mais as objetivações tornam-se diversificadas e complexas, maiores são as exigências para a formação de seus membros. Contudo, as especificidades do grau de desenvolvimento das relações sociais de produção nas

\footnotetext{
${ }^{4}$ A fim de evitar a repetição homem/mulher, no decorrer desse trabalho, utilizaremos a terminologia homem enquanto sinônimo de gênero humano, o qual é constituído por homens e mulheres.
}

\begin{tabular}{|l|l|l|l|l|} 
Revista Dialectus & Ano 1 & n. 1 & Julho-Dezembro 2012 & p. 129-142 \\
\hline
\end{tabular}


sociedades de classes, em função da divisão social do trabalho e da propriedade privada, acarretam a incorporação das objetivações sociais de forma desigual pelos homens.

Neste ínterim, vale frisar que a universalização do gênero humano não pressupõe, necessariamente, a formação de indivíduos cada vez mais universais e livres. Ao contrário. Em condições de exploração de uma classe social por outra, o processo de universalização do gênero humano sucumbe à produção de indivíduos cada vez mais unilaterais e limitados, alienados das riquezas materiais e espirituais criadas pelos homens. Neste pormenor, “A diferença entre o alcance do desenvolvimento genérico do homem e do homem particular, em uma mesma época, pode ser imensa" (BARROCO, 2007, p. 236).

Especificamente no capitalismo, as relações humanas regidas pela propriedade privada dos meios de produção subtraem do gênero humano o poder de atuação sobre a natureza, transformando-o em propriedade particular de alguns. Mészáros (2006) pontua que, sob a forma do capital, a universalidade é necessariamente cindida do homem, já que a própria humanidade está divorciada de suas potencialidades efetivas, restando à realização de suas potencialidades alienadas. "[...] Assim, ao invés de ampliar a gama de capacidades efetivas do indivíduo, o desenvolvimento capitalista termina restringindo e negando também as potencialidades humanas" (MÉSZÁROS, 2006, p. 258).

Conforme salientam Klein, Silva e Da Mata (2011), na medida em que aliena-se a maior parte das pessoas das potencialidades conquistadas socialmente, produz-se um abalo na formação humana. $\mathrm{O}$ analfabetismo e a precarização da aprendizagem de conteúdos científicos são, assim, manifestações de um processo mais amplo de alienação, posto que um sistema produtivo que articula um enorme desenvolvimento, mas também a expropriação dos bens produzidos, inevitavelmente produz uma educação marcada por essa mesma contradição (KLEIN, SILVA, DA MATA, 2011). Sob esta lógica, não é no indivíduo em si mesmo que se há de buscar a explicação para o fracasso escolar e seu produto inevitável: o jovem ou adulto de precária escolarização.

Nesta perspectiva, esses jovens e adultos precariamente escolarizados não são casos de anomalia ou desvio social, mas, ao contrário, são produtos normais da sociedade em que vivemos (VIEIRA PINTO, 1989). O adulto se torna precariamente escolarizado porque as condições materiais de sua existência lhe permitem sobreviver dessa forma.

A educação escolar é proporcionada, pois, nos estritos limites das necessidades objetivas da sociedade capitalista, ou seja, a fragmentação do trabalho decorrente da 
divisão técnica do trabalho impõe um modelo educacional igualmente fragmentário, que se expressa na formação do trabalhador enquanto adaptabilidade ao mercado de trabalho da forma mais precária, a qual se centra, por um lado, na perspectiva pragmática de adaptação às demandas do capital e, por outro, na precarização do conhecimento e na ausência de uma perspectiva da totalidade. Asseveramos que a escolarização de jovens e adultos trabalhadores, dirigida à formação de níveis mais elevados de consciência, demanda o desvelamento do processo da constituição e do desenvolvimento do modo de produção capitalista.A Psicologia, sob a concepção histórico-cultural, pode auxiliar neste sentido, na medida em que favorece explicações que explicitam as causas da constituição e do desenvolvimento humanos.

\section{Psicologia Histórico-Cultural e EJA: desnaturalização da precária formação escolar trabalhador}

Compreender a raiz material da alienação humana na sociedade capitalista - a alienação do trabalho - faz frente com a resignação da desumanização na realidade, à aceitação "natural" das condições humanas postas e engendra a compreensão que o processo que resulta na criação de seres humanos fragmentados pode ser revertido, a partir de mudanças radicais no modo de produção da humanidade. Esta era a defesa incondicional de Lev S. Vigotski ${ }^{5}$, A. Luria e A. Leontiev: a possibilidade real de superação da alienação do trabalho reinante na sociedade capitalista, sendo esta a condição vital para o aniquilamento da exploração do homem pelo próprio homem e para o início da "verdadeira história da humanidade" (MARX, [19--]). No contexto pósrevolucionário soviético, os autores se esforçaram para formular um novo tipo de Psicologia que compreendesse o homem a partir daquilo que produz e do modo como se reproduz.

Tinham clara a empreitada de que a atividade vital ao deixar de ser baseada na propriedade privada e na troca - sem a mediação alienante da divisão do trabalho na sociedade capitalista -, adquiriria o caráter da atividade do homem como ser genérico. Defendiam, portanto, que a liberdade humana de exercer os poderes essenciais do homem, cindidos pelas limitações criadas pelas reificadas relações sociais de produção

\footnotetext{
${ }^{5}$ Optamos por esta forma de representação do sobrenome do autor por ser a mais recente no Brasil e ser a forma utilizada na tradução literal da obra russa que chegou ao Brasil no ano de 2001 (A construção do pensamento e da linguagem), pela editora Martins Fontes. No entanto, podemos encontrar seu sobrenome grafado como Vygotsky, Vigotsky, Vygotski, Vigotskii, entre outras variações, conforme a tradução. Nas citações e referências, no presente texto, foi mantida a grafia utilizada no original.
}

\begin{tabular}{|l|l|l|l|l|} 
Revista Dialectus & Ano 1 & n. 1 & Julho-Dezembro 2012 & p. 129-142 \\
\hline
\end{tabular}


capitalista, pode ser alcançada a partir de mudanças radicais no modo de produção da humanidade. De acordo com Leontiev (1978, p. 173-174),

\begin{abstract}
Na sociedade de classes, a encarnação no desenvolvimento dos indivíduos dos resultados adquiridos pela humanidade na sequência do desenvolvimento da sua actividade global, e a de todas as aptidões humanas, permanecem sempre unilaterais e parciais. Só a supressão do reino da propriedade privada e das relações antagonistas que ela engendra pode pôr fim à necessidade de um desenvolvimento parcial e unilateral dos indivíduos. Só ela cria, com efeito, as condições em que o princípio fundamental da ontogênese humana - a saber, a reprodução nas aptidões e propriedades múltiplas formadas durante o processo sócio-histórico - se pode plenamente exercer.
\end{abstract}

Consoante ao materialismo histórico-dialético é explicitado nesta abordagem Psicologia Histórico-Cultural - que nenhuma sociedade pós-capitalista poderia ter esperanças de realizar o indivíduo social sem aniquilar aquilo que é especifico da sociedade de classes: a exploração do homem pelo próprio homem, a luta de classes, a propriedade privada.

No entanto, Vygotsky (2004) salienta que a produção tecnológica e objetivação do trabalho têm encaminhado, no decurso da história da humanidade, à produção de homens cindidos das potencialidades humanas, pois quanto mais a divisão do trabalho se impõe, mais degradado se torna o homem). Esta defesa corrobora com aquilo que Marx e Engels (1976, p. 28) postulavam: “A 'libertação' é um facto histórico e não um facto de intelectual, e é provocado por condições históricas [...]”.

Sob essa perspectiva, Vigotski compreende que a degradação humana não é inerente ao homem, mas é produzida em determinada época e por determinadas condições criadas pelos homens. É justamente por isso que pode ser superada, à medida que o trabalho se torne um fim em si mesmo, enquanto atividade interior, enquanto atividade livre não impeditiva dos poderes humanos.

Tal mudança não deriva de mudanças institucionais, mas como um processo complexo de mudanças estruturais e radicais em todas as partes da totalidade humana, inclusive na educação do povo para a transformação e elevação da consciência, para o aprimoramento dos instrumentos do pensamento, para o fortalecimento da personalidade e da individualidade, para o desenvolvimento das potencialidades e dos sentidos humanos e para formação do espírito de responsabilidade coletiva, questões candentes no contexto pós-revolucionário. Vygotsky (2004. p. 10-11) enfatiza que

A educação deve desempenhar o papel central na transformação do homem, nesta estrada de formação social consciente de gerações novas, a educação deve ser a base para alteração do tipo humano histórico. As novas gerações e suas novas formas de educação representam a rota principal que a história seguirá para criar o novo tipo de homem. Neste sentido, o papel da educação

\begin{tabular}{|l|l|l|l|l|} 
Revista Dialectus & Ano 1 & n. 1 & Julho-Dezembro 2012 & p. 129-142 \\
\hline
\end{tabular}


social e politécnica ${ }^{6}$ é extraordinariamente importante. As ideias básicas que justificam a educação politécnica consistem em uma tentativa de superar a divisão entre trabalho físico e intelectual e reunir pensamento e trabalho que foram separados durante o processo de desenvolvimento capitalista.

Vigotski é claro ao pontuar que a ciência, a arte e a filosofia, pautadas na instrução teórica, por si só não levam ao reino da liberdade; mas é firme ao esclarecer que a educação formal desempenha papel central na transformação do homem e na formação humana, na edificação da nova sociedade e novo homem. Empenho da ciência, portanto, à humanização, à educação para o povo e para o trabalho enriquecedor e criativo. Para tanto, a valorização do conhecimento cientifico e a vinculação do trabalho cotidiano com a teoria a todos era imprescindível para a promoção do homem desenvolvido, livre e rico, no sentido proposto por Marx. Sob esta concepção, Vigotski enfatiza que a formação do trabalhador deve caminhar passo a passo com a ciência, pois

Em semelhantes formas o trabalho se transforma em conhecimento científico
cristalizado e para adquirir habilidades é efetivamente necessário dominar um
imenso capital de conhecimentos acumulados sobre a natureza, que são
utilizados em cada aperfeiçoamento técnico. Pela primeira vez na história da
humanidade, o trabalho politécnico forma o cruzamento de todas as linhas
fundamentais da cultura humana que era impensável nas épocas anteriores. O
significado educativo desse tipo de trabalho é infinito porque, para dominá-lo
plenamente, é necessário o mais pleno domínio do material da ciência
acumulada por todos os séculos.
Por último, a questão mais importante: a influência puramente educativa
exercida pelo trabalho. Esse trabalho se transforma predominantemente em um
trabalho consciente e exige dos seus participantes uma suprema intensificação
da inteligência e da atenção, promovendo um labor do operário comum aos
níveis superiores do trabalho criador humano (VIGOTSKI, 2001, p. 257, 258).

Marx e Engels ao tratarem da educação ${ }^{7}$ pontuam que esta não constitui uma revolução por si mesma, mas é um instrumento importante para criar condições de superação daquilo que avilta o homem na sociedade de classes. Por via da educação é possível provocar o conhecimento da realidade, o desenvolvimento das funções

\footnotetext{
${ }^{6}$ Vygotsky (2004, p. 10-11 ) explica que "De acordo com Marx, a educação politécnica proporciona a familiaridade com os princípios científicos gerais a todos os processos de produção e, ao mesmo tempo, ensina as crianças e adolescentes que habilidades práticas tornam possível para eles operarem as ferramentas básicas utilizadas em todas as indústrias. Krupskaja formula esta ideia da seguinte maneira: 'Uma escola politécnica pode ser distinguida de uma escola de comércio pelo fato de centrar-se na interpretação de processos de trabalho, no desenvolvimento da habilidade para unificar teoria e prática e na habilidade para entender a interdependência de certos fenômenos, enquanto em uma escola de comércio o centro de gravidade está em proporcionar para os alunos habilidades para o trabalho'".

${ }^{7}$ Marx e Engels abordam a temática da educação em obras, como por exemplo, O Capital, escrita por Marx, em específico no capítulo XIII - A Grande Indústria; A Ideologia Alemã, elaborada por Marx e Engels entre os anos de 1845-1846; Crítica ao Programa de Gotha, produzida por Marx entre os anos de 1875 e 1878; Princípios do Comunismo, escrita por Engels em 1847 (BARROCO, 2007; LOMBARDI, 2005).
} 
psicológicas superiores e o aprimoramento da formação cultural, embora as condições históricas não estejam encaminhando para isso.

Notoriamente os autores soviéticos defendem, por um lado, a educação de qualidade para todos, para os trabalhadores e para sua prole; mas, por outro, entendem que é preciso criar condições que transcendam a educação que vigora na sociedade capitalista, já que neste modo de produção a educação igualitária é ilusória.

Fica, assim, evidente, que os pressupostos teóricos desta escola psicológica além de possibilitar pensar sobre os resultados e consequências da educação sob os moldes da sociedade capitalista, nos permite refletir sobre as suas causas e ter uma visão prospectiva do que pode ser feito. Tomando por base Marx e Engels, os autores soviéticos defendem que as transformações dependem dos homens concretos, sendo fundamental a apreensão das leis que regem o funcionamento da sociedade para que, dialeticamente, ocorra uma atuação ativa que, se não modifica a realidade posta, cria condições para modificações significativas no nível de consciência dos indivíduos sobre a sua condição de ser datado e histórico.

Os autores da Psicologia Histórico-Cultural destacam a essencialidade da educação sistematizada no desenvolvimento do psiquismo, na estruturação dos processos psicológicos. Se, por um lado, explicitam que a escola por si mesma não gera mudanças radicais na sociedade por não ser independente das relações econômicas e sociais, por outro, revelam a essencialidade da educação formal para transformação e elevação da consciência, para o aprimoramento dos instrumentos do pensamento, para o desenvolvimento das potencialidades e dos sentidos humanos.

\section{Considerações finais}

A análise sobre a precária formação escolar, sob os fundamentos do materialismo histórico-dialético e da Psicologia Histórico-Cultural, evidencia que a EJA está amarrada ao fio da história do desenvolvimento das forças produtivas capitalistas. Essa modalidade é, pois, uma expressão desta época histórica e está em consonância com o discurso ideológico e com as concepções jurídica e política de igualdade e liberdade do pensamento liberal que alicerçam as relações capitalistas e ofuscam a exacerbação das contradições e luta de classes deste sistema produtivo. Barroco (2007) salienta que nesta fase, em que se tornam mais agudas as contradições do processo de reprodução sóciometabólica do capital, é preciso entender que não se pode falar de

\begin{tabular}{|l|l|l|l|l|} 
Revista Dialectus & Ano 1 & n. 1 & Julho-Dezembro 2012 & p. 129-142 \\
\hline
\end{tabular}


propostas de inclusão social e escolar - como é o caso da EJA - sem atentar para as contradições existentes entre trabalho e educação.

É preciso esclarecer que não somos contra a proposição desta modalidade de ensino. Mas não basta ser contra ou a favor, é fundamental buscar propostas e enfrentamentos pautados na razão e não na emoção ou no julgamento moral (BARROCO, 2004). Se não conhecermos a lógica histórica que movimenta tais propostas, caímos no discurso do "desafio social" de combater a "dívida aos sujeitos marginais do sistema" e não nos atentamos ao porquê da existência dos marginalizados e como a educação de adultos se constituiu enquanto modalidade de ensino no Brasil.

Se não entendemos as causas reais dos limites da escolarização dos adultos somos conduzidos à armadilha ideológica que difunde a ideia que as possibilidades para o estudo estão postas, mediante os inúmeros programas disponibilizados pelo governo e pela sociedade civil, bastando aproveitá-las para ter vida melhor e fazer do mundo um lugar melhor para se viver. A educação, aqui, ganha status de redentora da sociedade.

Sair dos limites da escola e apreender o que movimenta a não aprendizagem de determinados conhecimentos é o que pode mobilizar ações concretas de enfrentamento para revolucionar a consciência e os instrumentos do pensamento, para a complexificação dos sentidos humanos, enriquecendo a formação do trabalhador.

\section{Referências Bibliográficas}

ALVES, G. L. A produção da escola pública contemporânea. Campo Grande, MS: Ed. UFMS; Campinas, SP: Autores Associados, 2001.

BARROCO, S. M. S. Considerações sobre uma prática educacional inclusiva em tempos de prática social excludente. IN: Proposta Curricular para a Educação Especial: norteadores teóricos. Sarandi: Orfeu Gráfica e Editora Ltda., 2004, p. 15-22.

BARROCO, S. M. S. A Educação Especial do novo homem soviético e a Psicologia de L. S. Vigotski: implicações e contribuições para a Psicologia e a Educação atuais. 414 p. Tese de Doutorado - Programa de Pós-Graduação em Educação Escolar da Universidade Estadual Paulista, Araraquara, 2007.

BRASIL. Lei de Diretrizes e Bases da Educação Nacional. Lei no 9.394 de 20 de dezembro de 1996. Diário Oficial da União, Brasília, DF, 23 dez. 1996. 
BRASIL. Conselho Nacional de Educação. Câmara de Educação Básica. Parecer n ${ }^{\circ} .11$, homologada em 07 de junho de 2000. Diretrizes Curriculares para a Educação de Jovens e Adultos. Brasília: MEC, 2000.

BRASIL, Ministério da Educação. Documento Base - Programa Nacional de Integração da Educação Profissional com a Educação Básica na Modalidade de Educação de Jovens e Adultos - Educação Profissional Técnica De Nível Médio/Ensino Médio. Brasília: MEC/SETEC, 2007.

DUARTE, N. A Individualidade Para-Si: Contribuição a uma Teoria Histórico-Social da Formação do Indivíduo. Campinas: Autores Associados, 1993.

IBGE. Síntese de Indicadores Sociais: uma análise das condições de vida da população brasileira 2010. Rio de Janeiro: IBGE, 2010a.

IBGE. Pesquisa Nacional por Amostra de Domicílios. Rio de Janeiro: IBGE, 2010b.

IBGE. Censo Demográfico 2010. Disponível em http://www.ibge.gov.br/home/presidencia/noticias/noticia_visualiza.php?id_noticia=201 7\&id_pagina=1. Acesso em dezembro de 2011.

KLEIN, L. R.; SILVA, G. L. R. da; DA MATA, V. A. Alienação ou exclusão: refletindo o processo de inclusão na educação de jovens e adultos. IN: FACCI, Marilda Gonçalves Dias; MEIRA, Marisa Eugênia Melillo; TULESKI, Silvana Calvo. Exclusão e inclusão: falsas dicotomias, Maringá: EDUEM, 2011.

LEONTIEV, A. N. O desenvolvimento do psiquismo. Tradução de Manuel Dias Duarte. Lisboa: Livros Horizonte, 1978.

LOMBARDI, J. C. Educação, Ensino e Formação Profissional em Marx e Engels. IN: LOMBARDI, J. C.; SAVIANI, D. (orgs.). Marxismo e educação: debates contemporâneos. Campinas, SP: Autores Associados: HISTEDBR, 2005. (p. 1-38).

MÁRKUS, G.. Teoria do Conhecimento no Jovem Marx. Rio de Janeiro: Paz e Terra, 1974.

MARX, K. Prefácio à Contribuição à Crítica da Economia Política [1859]. IN: Obras Escolhidas de Karl Marx e Friedrich Engels. V. 1. São Paulo: Ed. Alfa - Omega, [19--], p. 300-303.

MARX, K.; ENGELS, F.. A Ideologia Alemã. Tradução de Conceição Jardim e Eduardo Lúcio Nogueira. $3^{\mathrm{a}}$ ed. Vol. I. Rio de Janeiro: Martins Fontes; Lisboa: Editorial Presença, 1976. Coleção Síntese.

MÉSZÁROS, I.. A teoria da alienação em Marx. Tradução de Isa Tavares. São Paulo: Boitempo, 2006.

NETTO, J. P.. Questão social no Brasil. Matinhos, PR: UFPR Litoral, 23 ago. 2008. Palestra de abertura do Curso de Especialização em Serviço Social da UFPR Litoral. 2008. 
VIEIRA PINTO, Á.. Sete lições sobre Educação de Adultos. $6^{\text {a }}$ ed. São Paulo: Autores Associados: Cortez, 1989. (Coleção Educação Contemporânea).

VIGOTSKI, L. S.. Psicologia Pedagógica. Tradução de Paulo Bezerra. São Paulo: Martins Fontes, 2001b.

VYGOTSKY, L. A Transformação socialista do homem 1930. Trad. Nilson Dória. Marxists Internet Archive, 2004. Disponível em: http://www.marxists.org/portugues/vygotsky/1930/atransformacaosocialistadohomem.ht m. Acesso em: outubro de 2009. 